\title{
The Research and Analysis of Teaching Pattern Reform Based on Synergistic Learning
}

\author{
Xiuheng Zhang \\ The college of mechanical engineering \\ University of Ligong Shenyang \\ Shenyang, China \\ aeh25@126.com
}

\author{
Peng Ba \\ The college of mechanical engineering \\ University of Ligong Shenyang \\ Shenyang, China \\ bpbpppp@163.com
}

\begin{abstract}
Based on synergistic learning theory, this paper presents the teaching pattern reforms on mechanical courses. The methods and teaching pattern are explored to implement the synergistic in the course for interchangeability and measurement technical. And they are applied into actual teaching and have achieved good results. The experiences are gained and the results analyzed and evaluated. It has important practical significance for the study to introduce the pattern to other professional courses.
\end{abstract}

Keywords-synergistic learning system; teaching pattern; teaching reform; teaching evaluation

\section{INTRODUCTION}

As the development of information and multimedia technology, Tertiary education has tremendous change in the teaching mode, educational philosophy and other aspects. Students receive knowledge and learn through more variety styles rather than only in the classroom. So the focus of the study are how to introduce advanced teaching philosophy in the curriculum, how to guide students to choose suitable learning methods, how to improve the current education model. According to "national long-term education reform and development plan" [1], our team has been working on the reform for teaching models and concepts to mechanical courses for several years. We have achieved some results and experiences. This paper discusses the implementation of synergistic theory in open synergistic learning models. And the online synergistic learning platform is applied in teaching. A rational evaluation system of teaching is established.

\section{THEORETICAL FOUNDATIONS AND MECHANISM FOR TEACHING MODE REFORM}

The teaching mode reform is depended on synergistic learning theory foundation. Synergistic learning theory includes cognitive psychology, learning psychology, and constructivism and so on. Under the learning environment for information age, memory theory of cognitive psychology are used in synergistic learning process to provide more interactive way so that learners can exchange the information with others. After interaction, reflection, strengthening and reconstruction of knowledge, the purpose of cognition is achieved. The organic, synergistic relationship can be built between the existing information, knowledge, behavior, and culture. The existing restrictions of learning behavior are broken. Learners pay more attention to the interaction and sharing of knowledge.
The synergistic environment needs to provide learners with platform for group-thinking and construction mechanism.

To achieve the synergy concept, synergistic teaching platform are established. And synergistic teaching mechanism is important for learner to establish in teaching model reform. in this learning system, the aggregation mechanism is established to make the personal and organizational information collected, aggregation, storage, and shared. The learning system is maintained completely between media, information, students and teachers. To this end, the basic mechanisms of synergistic learning system is summarized as: " interaction deeply, converging and sharing, collective thinking, cooperation and constructed, multi- field coordination " [2] .

\section{A. Teaching mode reform process applications}

Based on the above understanding of the synergistic mechanisms, the study is to make a reform in the teaching methodology of "interchangeability and measuring technology. Firstly, the traditional teaching mode is changed. Based on computer and network technology, the synergies learning platform are built. On the one hand, the appropriate teaching programs are analyzed and developed to focus the student groups on the important knowledge. On the other hand, the practice teams are setup to make a classroom learning community to study and practice. Learning from each other to fulfill the task by cooperates.

\section{B. Reform of teaching programs}

To solve the drawbacks of the traditional teaching, considering the synergistic learning, the process of the synergistic learning process as three stages:

- Information gathering: the curriculum for interchangeability and measuring technology is divided into several thematic. They are independent between each other and interlinked.

- Group-thinking: through using of comparison, classification, sort, merge, delete, add and other means, make students an ordered structure of thematic knowledge points.

- Knowledge construction: according to the initial recognition, the students set up the study groups to construct on the information together. Facing common tasks, students make the learning resources eventually transform into design capabilities by collaborate. 
In reform of teaching program, there are two important contents, one is building synergistic learning environment to support student learning activities orderly, the other is implement learning activities to achieve self-construction.

Build synergistic learning space: considering this course characteristics and teaching content to real-time updated, the synergistic learning space are built under the guidance of technical standards, shown in Figure 1 :

The composition of synergistic learning group: To finish the different learning tasks, there are usually 3-5 members in a group according to cognitive ability, personality, hobbies and other aspects of the students, as shown in figure 2.

\section{Practice process}

- The object of practice: all sophomores of mechanical engineering , including mechanical design, electro-mechanical, mechanical manufacturing and automation, hydraulic and industrial engineering.

- Teaching programs: Based on the "synergistic learning theory ", the full teaching in classroom is changed into the form of some academic reports to note the interpretations, the remainder is carried on the platform of synergistic learning system, including variety of learning tasks and design issues set in the system.

- Building the synergistic learning platform: make the framework, behavioral conventions, system, as well as a variety of operating units (synergistic learning tools) aided by network technology.

- Preparing of new materials, problem sets, training guide books, and establishing other teaching resources such as online resources, discussion platform, etc.

- Improving for teaching methods: theory classes are replaced by academic reports form by the synergistic learning groups established spontaneously by students or instructors. Tasks can inspire students to study actively and cooperate with the students as team spirit. No exams, but evaluate the results through the evaluation system of synergistic learning system.

\section{Teaching evaluation mechanism}

It is necessary to develop appropriate evaluation system to evaluate student learning outcomes. As the outcome of synergistic learning is reflected in completing the task, it is obviously not suitable to evaluate this course by test scores. The appropriate evaluation system is given based on the actual situation as shown in (1):

A student's grades:

$$
L=\alpha+\varepsilon 1 * X 1+\varepsilon 2 * X 2+\cdots+\varepsilon n * X n
$$

Where: $\alpha$ is the usual student achievement;

$\mathrm{X} 1, \mathrm{X} 1 \ldots \mathrm{Xn}$ is the completion achievements of tasks Task $1 \ldots \mathrm{n}$;

$$
\varepsilon 1, \varepsilon 2 \ldots \varepsilon n \text { is weighting factor of subtasks score; }
$$

\section{EFFECTIVENESS ANALYSIS ABOUT SYNERGISTIC LEARNING TEACHING}

Shorten the learning time: With synergistic learning system, students' learning time is reduced by a half or more. And the system provides students with more opportunities to think and practice operations.

Improve teaching effectiveness: With synergistic learning system, the active participation of students is promoted to ensure the learning progress. The group participants will guide each other, and some members may act as a tutor's role. "

\section{CONCLUSION}

According to synergistic learning theory, learners should be provided with effective synergistic environment and toolkit support under network based teaching environment. This Paper further develops synergistic Learning in the course for interchangeability and measurement technical, via testifying the feasibility and effectiveness of synergistic learning, by instructional and empirical test of synergistic learning environment, which probes in to learning modes under IT support.

\section{ACKNOWLEDGMENTS}

This work is founded by Liaoning Education Science "12th five-year-plan" JG12DB293 " Constructivist Learning Theory in Mechanical bilingual teaching" and Liaoning Higher Education Reform for 2012: Exploration and Practice of Teaching Mode for Interchangeability and Measurement Technology based on the collaborative learning.

\section{REFERENCES}

[1] Zhiting Z. Synergistic Learning: A New Learning Paradigm in Connected Age[C]//Keynotes on Advanced Seminar of 1st Global ET Summit Conference. Shanghai, China. 2006, 30.

[2] Wang F, Hannafin M J. Design-based research and technology-enhanced learning environments[J]. Educational Technology Research and Development, 2005, 53(4): 5-23.

[3] Connectivism: A Learning Theory for the Digital Age[EB/OL] http:// www.elearnspace.org/Articles/connectivism.htm,2009.03-23.

[4] Wang Y. Construction and Application of Synergistic Learning System [D]. Shanghai: East China Normal University, 2009,

[5] Zeng H, Ma J. Application of Network Synergistic Learning System [J]. China Educational Technology, 2005, 1: 84-87. 


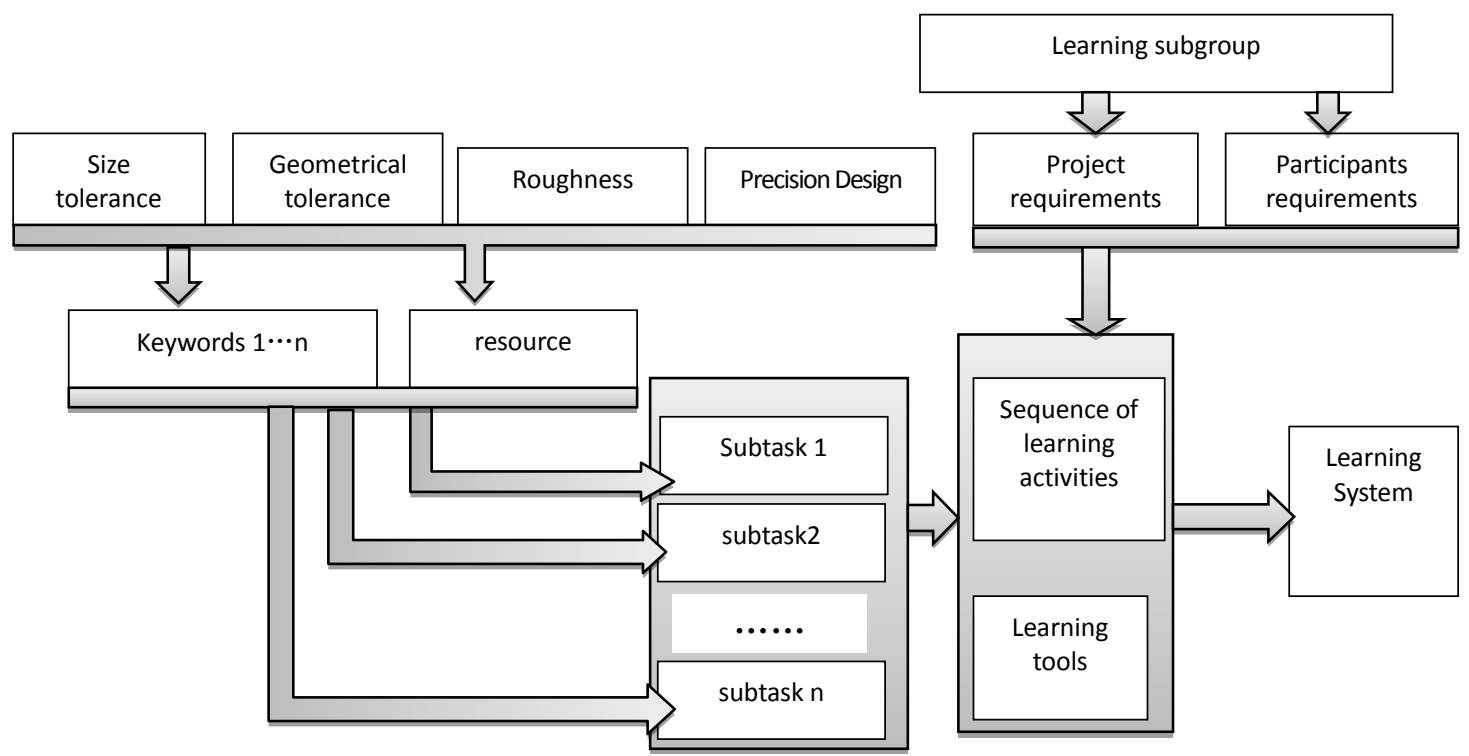

Fig.1 The diagram of space environment with synergistic learning

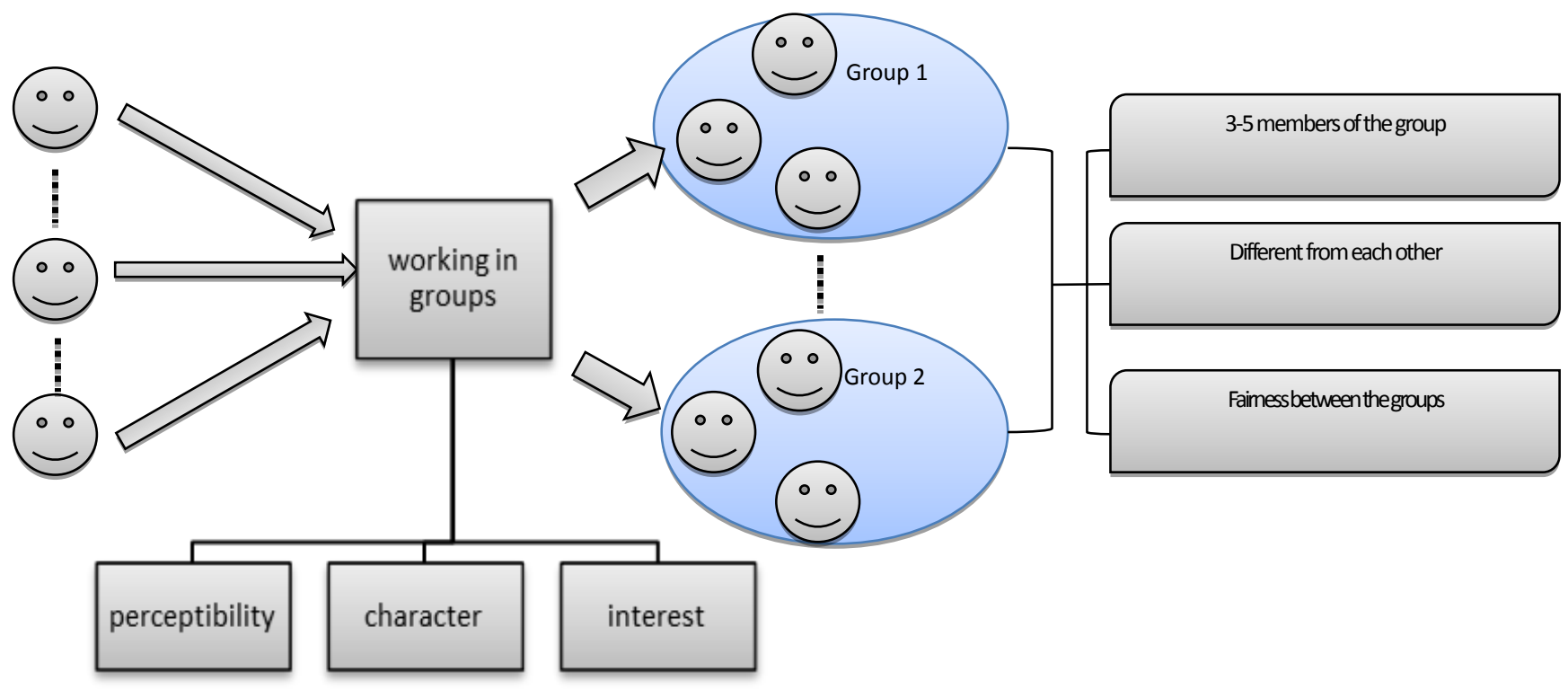

Fig.2 The diagram of students in groups 